http://jmscr.igmpublication.org/home/

ISSN (e)-2347-176x ISSN (p) 2455-0450

crossref DOI: https://dx.doi.org/10.18535/jmscr/v10i2.30

Journal Of Medical Science And Clinical Research

\title{
Vigilant Approach to Intramyometrial Vasopressin in Obstetrics- A Case Report
}

\author{
Author \\ Dr Trishagni Talukdar \\ Department of Anaesthesia and Critical Care, Silchar Medical College and Hospital, Assam, India \\ Corresponding Author \\ Dr Trishagni Talukdar \\ Guwahati-781003, Assam
}

\begin{abstract}
Vasopressin is a naturally occurring hormone, Vasopressin has multiple effects on different organ systems; however, its primary effect of vasoconstriction finds a place gynaecology surgery to decrease blood loss. As myomas are very vascular tumour, so to reduce significant blood loss and lessen morbidity local vasopressin injection is especially useful. Many potential complications (mainly cardiovascular) of Vasopressin use in gynaecologic procedures have been reported to occur. In the present case, described here the patient received $20 \mathrm{U}$ of vasopressin in dilution of $0.2 \mathrm{U} / \mathrm{ml}$ after which patient experienced severe bradycardia which was managed quickly. Here we discuss the serious cardiovascular complications of intramyometrial vasopressin, need for use of proper dose and dilution and early anticipation and quick management of potential lethal side effects in patients.

Keywords: vasopressin, bradycardia, intramyometrial.
\end{abstract}

\section{Introduction}

Uterine leiomyomas, commonly called fibroids are benign tumours of uterine myometrium composed of smooth muscle with variable amount of connective tissue. It is the commonest tumour of the female pelvic organ ${ }^{1}$. As it is vascular tumour, many a times Myomectomy leads severe intraoperative blood loss. It is estimated that the average volume of blood loss during abdominal myomectomy ranges between $200-400 \mathrm{ml},{ }^{2,3,4}$ with blood loss greater than $1000 \mathrm{ml}$ considered as major blood loss. ${ }^{5}$ Vasopressin is a synthetic analogue of the anti-diuretic hormone, has a V1 receptor agonistic action thereby causes vasoconstriction . Intramyometrial injection of vasopressin helps to reduce significant intraoperative blood loss. However, it is not devoid of side effects and sometimes might cause very serious complications like arrhythmias, bradycardia, pulmonary oedema, and cardiac arrest. Here we are presenting a case report of sudden severe bradycardia caused by intramyoma diluted vasopressin injection and discussion on management of such patients.

\section{Case Report}

A 29 year female presented to gynaecology department in our hospital, Silchar medical college and hospital, Assam, India with c/o heavy menstrual bleeding for 2 years and primary 
infertility. She was diagnosed to have Myoma (size approx. $6.5 \times 5.7 \times 6 \mathrm{~cm}$ ) and was planned for myomectomy under regional anaesthesia. The patient weighing $62 \mathrm{~kg}$ underwent pre anaesthetic check-up and cleared under American society of anaesthesiologist grade II.

Patient was transfused 2 units of PRBC 1 day prior to surgery in view of anaemia ( $\mathrm{Hb} 6.6 \mathrm{gm} \%)$ and post transfusion $\mathrm{Hb}$ was $8 \mathrm{gm} \%$.All the preoperative investigations and airway assessment was done and found to be within normal range. In night before OT, Patient was given $0.5 \mathrm{mg}$ alprazolam to relieve anxiety. In the operation theatre, standard routine monitoring was initiated which showed non invasive BP 116/72 mmhg, pulse rate 80/min, SpO2 98\% on Room air.( Pre op vitals)An intravenous line was secured with 18 $\mathrm{g}$ canula on right hand and coloading was performed with Ringer's lactate solution. Combined spinal epidural block was given in the L3-L4 interspace using a spinal needle and $3 \mathrm{ml}$ of $0.5 \%$ bupivacaine with $25 \mu \mathrm{g}$ fentanyl was administered in the subarachnoid space. Within 68 mins, T6 sensory block level was achieved. Through a face mask Oxygen was administered to the patient. The patient remained hemodynamically stable following subarachnoid block (SAB).

Approximately 45 mins of surgery, surgeons injected $100 \mathrm{ml}$ of $(0.2 \mathrm{U} / \mathrm{ml}$ of vasopressin, i.e., 20 units vasopressin diluted in $100 \mathrm{ml}$ of $0.9 \% \mathrm{NS}$ ) into the myometrium after confirming negative aspiration of blood. Within 2 mins, the patient developed bradycardia with HR less than $38 / \mathrm{min}$, blood pressure (BP) fell to 78/39mmhg, while ECG complexes were normal. The radial and brachial arteries were feeble to palpate. Patient was seen to be restlessness\& complaining of Nausea. Immediately Atropine $0.6 \mathrm{mg}$ was administered. IV fluids $(1000 \mathrm{ml}$ of $\mathrm{NS})$ were given in bolus dose through wide bore IV canula in both hands. Patient was put on Bag and mask ventilation with $100 \%$ oxygen. Defibrillator and all resuscitative drugs and equipment's were kept in standby. Patients Conjunctiva and tongue appeared pale. The patient did not have any symptoms of headache, chest pain, palpitation, difficulty in breathing during this period. Level of sensory blockade was rechecked, found to be below T6. After 5 mins, vitals improved with heart Rate 134/86 mmhg and Pulse Rate of 100/min. within 15 mins; colour of conjunctiva appeared normal. It was decided to continue with surgery. The surgery did not have any untoward events after that $\&$ whole procedure completed in approximately 90 mins. Patient monitored in recovery room for $24 \mathrm{hrs}$.

\section{Discussion}

Vasopressin is a naturally occurring hormone produced by magnocellular neurons of the hypothalamus and secreted by the posterior lobe of the pituitary gland. Vasopressin has a multitude of effects on different organ systems; however, its primary effect of vasoconstriction is what has attracted gynecologic surgeons.

Vaspressin use in gynaecology surgery as haemostatic agent are found in reports as early as 1959. ${ }^{6}$ After that, many studies have been done worldwide in this regard \& its role to reduce intraoperative blood loss has been established.

Vasopressin has got 3 distinct receptors through which itexerts its actions. The V1 receptor is located throughout the vascular tree, especially the capillaries, small arterioles, and venules, and less on the larger veins, and on smooth muscle throughout the body, particularly the gastrointestinal tract.

The uterus mainly has this $\mathrm{V} 1$ receptors ${ }^{\mathbf{7 , 8}}$, activation of which causes vasoconstriction and smooth Muscle contraction ${ }^{[11]}$.

The V2 receptor is located in the epithelial principal cellsof the collecting duct of the kidney through which vasopressin helps to regulate extracellular fluid osmolality.

As myomas are very vascular tumour, so to reduce significant blood loss and lessen morbidity local vasopressin injection is especially useful. Vasopressin causes increased myometrial contractility $^{7,8,9}$. 
The vasoconstrictive effects of intramyometrial vasopressin manifest within seconds with a half life of 10-20 min and a duration of action of 2-8 h ${ }^{10}$.The injection of diluted vasopressin into the plane between the myoma and myometrium leads to vasoconstriction of the feeding vessels (capillaries, small arterioles and venules) for 4560 min which is usually sufficient for the myometrial suturing to be completed and therefore reducing the blood flow to the myoma and decreasing the blood loss during the excision of the myoma.

Thiek et al. ${ }^{11}$ found that vasopressin significantly decreased the blood loss and blood transfusion requirement during myomectomy in 35 patients in a case control studies.

$\mathrm{Al}$ though its vasoconstrictive effects are strongest locally in the area of administration, systemic effects happen sometimes. Many potential complications (mainly cardiovascular) of Vasopressin use in gynaecologic procedures have been reported to occur.

For these untoward effects, several European countries have put ban on its use.

Hobo et al. ${ }^{12}$ reported a case of sudden cardiac arrest after intramyometrial vasopressin (11.2 units, 0.2 unit $/ \mathrm{ml}$ ) and also Nerurkar et al. ${ }^{22}$ reported a similar complication. Hung et al. ${ }^{10}$ reported two cases of bradycardia followed by cardiac arrest and pulmonary oedema with intramyometrial vasopressin (12-20 units, 2 unit $/ \mathrm{ml}$ ) and similar complications were described by other studies. ${ }^{13,14}$ Severe hypotension was reported by Nezhat et al., ${ }^{15}$ and Chilkoti et al. ${ }^{16}$ Deschamps et al. ${ }^{\mathbf{1 7}}$ in a patient found severe bradycardia and atrioventricular block with bigeminy after injecting $3 \mathrm{U}$ intramyometrial vasopressin.

Kitamura et al. ${ }^{7}$ in a case report, described severe hypotension, bradycardia in addition to STsegment depression and premature ventricular contractions in the ECG when a patient received vasopressin injection (7.9 units, 0.2 unit $/ \mathrm{ml}$ ) during laparoscopic myomectomy and the similarreports were described by Lurie et al. ${ }^{\mathbf{1 8}}$
Lee et al. ${ }^{19}$ described a case of severe bradycardia (26 bpm) followed by cardiac arrest after intramyometrial injection of vasopressin (20 units, $0.5 \mathrm{unit} / \mathrm{ml}$ ) and with immediate atropine administration heart rate came to normal. Kabade et al. ${ }^{20}$ described a case of bradycardia, severe hypotension, cardiac arrest after intramyometrial vasopressin (8 units, 0.2 unit $/ \mathrm{ml}$ ). After resuscitation, the patient recovered, but the haemodynamic was severely unstable even with inotropic support, and. the patient succumbed postoperatively.

The possible causes of these complications may be linked to the severe vasopressin induced hypertension, severe bradycardia, and cardiac arrest because of large dose or accidental intravascular administration. The vasoconstrictive effect of vasopressin causes coronary artery vasospasm that causes cardiac ischaemia, infarction, and arrest. In the literature across many last years on intramyometrial vasopressin, it does not reveal any definite dose or dilution which can be considered safe from serious cardiovascular complications. Even (lower doses (3-11 units $)^{12,15,21,13,17,22}$ and concentration $(0.1$ unit $/ \mathrm{ml})^{23}$ have resulted bad outcomes sometimes. Butala et al. ${ }^{24}$ recommended $0.05-0.3 \mathrm{U} / \mathrm{ml}$ concentration of dilute vasopressin to avoid its serious complications.

Dose and dilution of vasopressin, both are important in predicting as well as alleviating the risks of lethal complications. Dilution helps to make sure there is less risk to patients in case of inadvertent intravascular injection, also helps in diffusion through a larger area.

In the present case, described here the patient received $20 \mathrm{U}$ of vasopressin in dilution of $0.2 \mathrm{U} / \mathrm{ml}$ after which patient experienced cardiac side effects. Most trials typically used concentrations of $0.2 \mathrm{U} / \mathrm{mL}$. With regards to dose, multiples studies \& reports published have concluded to use lowest possible dose to stop bleeding. However, that is a vague term, as even lower doses also sometimes harm the Cardiovascular system. So best advice would be to 
remain overly cautious, anticipation of immediate bad outcomes, and being ready handedness to manage any untoward events after vasopressin injection.

It would be prudent not to use or careful use of vasopressin in patients with pre-existing coronary artery disease, ventricular dysfunction or arrhythmias, hypomagnesemia, or peripheral vascular disease.

\section{Conclusion}

Though the use of intramyometrial vasopressin decreases blood loss and blood transfusion, it is especially important to appropriately select the patients and use of minimal dose and adequate dilution just to help the purpose. It is on the part of both gynaecologists and anaesthesiologists for taking necessary precautions, be alerted to manage potential life threating complications of intramyometrial vasopressin.

\section{Conflict of Interest: None}

\section{References}

1. Marshall LM, Spiegelman D, Barbieri RL, Goldman MB, Manson JE, Colditz GA, et al. Variation in the incidence of uterine leiomyoma among premenopausal women by age and race. Obstet Gynecol. 1997; 90:967-973.

2. Iverson RJ, Chelmow D, Strohbehn K, Waldman L, Evantash E. Relative morbidity of abdominal hysterectomy and myomectomy for management of uterine leiomyomas. Obstet Gynecol. 1996;88:415-419.

3. West S, Ruiz R, Parker WH. Abdominal myomectomy in women with very large uterine size. Fertil Steril. 2006;85:36-39.

4. Sawin SW, Pilevsky ND, Berlin JA, Barnhart KT. Comparability of perioperative morbidity between abdominal myomectomy and hysterectomy for women with uterine leiomyomas. Am J Obstet Gynecol. 2000;183:1448- 1455.
5. Harris WJ. Early complications of abdominal and vaginal hysterectomy. Obstet Gynecol Surv. 1995;50:795-80

6. Dillon TF. Vasopressin as a hemostatic in gynecologic surgery. Am J Obstet Gynecol. 1959;78:1285-1291

7. Kimura T, Kusui C, Matsumura Y, et al. Effectiveness of hormonal tourniquet by vasopressin during myomectomy through vasopressin V1a receptor ubiquitously expressed in myometrium. Gynecol Obstet Invest. 2002;54:125-131.

8. Maggi M, Del Carlo P, Fantoni G, et al. Human myometrium during pregnancy contains and responds to V1 vasopressin receptors as well as oxytocin receptors. $\mathbf{J}$ Clin Endocrinol Metab. 1990;70:11421154.

9. Helmer H. Oxytocin and vasopressin 1a receptor gene expression in the cycling or pregnant human uterus. Am J Obstet Gynecol. 1998;179: 1572-1578.

10. Hung MH, Wang YM, Chia YY, Chou YM, Liu K Intramyometrial injection of vasopressin causes bradycardia and cardiac arrest - report of two cases. Acta Anaesthesiol Taiwan 2006; 44:243-247.

11. Thiek JL, Choudhury SS, Ali J. Vasopressin in myomectomyeffectiveness and its sequelae. New Indian J OBGYN 2016;3:24-8

12. Hobo R, Netsu S, Koyasu Y, Tsutsumi O. Bradycardia and cardiac arrest caused by intramyometrial injection of vasopressin during a laparoscopically assisted myomectomy. Obstet Gynecol 2009; 113:484-6.

13. Kim SY, Lee JH, Bang EC, Lee HS, Kang YI, Cho KS, et al. Pulmonary edema following intramyometrial injection and paracervical infiltration of vasopressin during laparoscopic myomectomy and LAVH (Laparoscopic abdominal vaginal hysterectomy): A report of 2 cases. Anesth Pain Med 2010;5:333-7. 
14. Tulandi T, Beique F, Kimia M. Pulmonary edema: A complication of local injection of vasopressin at laparoscopy. Fertil Steril 1996;66:478-80

15. Nezhat F, Admon D, Nezhat CH, Dicorpo JE, Nezhat C. Life-threatening hypotension after vasopressin injection during operative laparoscopy, followed by uneventful repeat laparoscopy. J Am Assoc Gynecol Laparosc 1994;2:83-6

16. Chilkoti G, Mohta M, Nath S, Saxena AK, Khurana P. Anesthetic concerns with intramyometrial vasopressin during myomectomy. Ain Shams J Anaesthesiol 2016;9:452-4.

17. Deschamps A, Krishnamurthy S. Absence of pulse and blood pressure following vasopressin injection for myomectomy. Can J Anaesth 2005;52:552-3.

18. Lurie S, Mamet Y. Transient myocardial ischemia may occur following subendometrial vasopressin infiltration. Eur J Obstet Gynecol Reprod Biol 2000;91:87-9.

19. LeeGG, BaekSY, Woo KimT, JeongCY, RyuKH, ParkDH. Cardiac arrest caused by intramyometrial injection of vasopressin during a robotic-assisted laparoscopic myomectomy. J Int Med Res 2018;46:5303-8

20. Kabade SD, Sachidananda R, Wilson E, Divater SB. Intramyometrial vasopressin: A fear for anesthetist? Saudi J Anaesth 2017;11:494-5.

21. Malla UJ, Rong ZS. Role of vasopressin in myomectomy. IJSIT 2018;7:183-7.

22. Frishman G. Vasopressin: If some is good, is better? Obstet Gynecol 2009;113:476-7.

23. Karna ST, Pandey CK, Pandey VK, Dhankhar M. Bradycardia induced polymorphic ventricular tachycardia during living donor liver transplantation. Indian J Anaesth 2016;60:610-2

24. Butala BP, Shah VR, Parikh BK, Jayaprakash J, Kalo J. Bradycardia and

\section{severe vasospasm}

caused

by intramyometrial injection of vasopressin during myomectomy. Saudi J Anaesth 2014; 8:396-398. 